\title{
Thermal and ultraviolet-visible light stability kinetics of co-nanoencapsulated carotenoids
}

\author{
Médelin Marques da Silva ${ }^{a}$, Karina Paese $^{b}$, Silvia Stanisçuaski Guterres ${ }^{b}$, \\ Adriana Raffin Pohlmann ${ }^{c}$, Josiane Kuhn Rutz ${ }^{a}$, \\ Rufino Fernando Flores Cantillano ${ }^{d}$, Leonardo Nora ${ }^{a}$, \\ Alessandro de Oliveira Rios ${ }^{e, *}$
}

\author{
a Departamento de Ciência e Tecnologia de Alimentos, Universidade Federal de Pelotas (UFPel), Pelotas, RS, CEP \\ 96010-900, Brazil \\ b Programa de Pós-Graduação em Ciências Farmacêuticas, Faculdade de Farmácia, Universidade Federal do Rio \\ Grande do Sul (UFRGS), Porto Alegre, RS, CEP 90610-000, Brazil \\ c Departamento de Química Orgânica, Instituto de Química, Universidade Federal do Rio Grande do Sul (UFRGS), \\ Porto Alegre, RS, CEP 91501-970, Brazil \\ d Empresa Brasileira de Pesquisa Agropecuária (Embrapa), 9 Distrito, Monte Bonito, Pelotas, RS, CEP 96010-971, \\ Brazil \\ e Instituto de Ciência e Tecnologia de Alimentos, Universidade Federal do Rio Grande do Sul (UFRGS), Porto Alegre, \\ RS, CEP 91501-970, Brazil
}

\section{A R T I C L E I N F O}

\section{Article history:}

Received 4 October 2016

Received in revised form 19 April 2017

Accepted 17 May 2017

Available online 1 July 2017

\section{Keywords:}

Degradation kinetics

Heat-stability

Photo-stability

$\beta$-Carotene

$\alpha$-Carotene

Lutein

\begin{abstract}
A B S T R A C T
Lipid-core nanocapsules loaded with $\beta$-carotene and $\alpha$-carotene, and lutein (NCs) were produced with monomodal particle size distribution. Their mean diameter was $151.33 \pm 5.03 \mathrm{~nm}$ $\left(\mathrm{D}_{4,3}\right)$ and $180.30 \pm 0.70 \mathrm{~nm}$ ( $\mathrm{z}$-average), zeta potential was $-22.63 \pm 0.52 \mathrm{mV}$, and $\mathrm{pH}$ was $3.21 \pm 0.04$. The stability of NCs was studied under different simulated industrial treatments, such as thermal and ultraviolet (UV)-visible light treatment. Regardless of the temperature and incubation time of the samples, higher carotenoids retention (\%) was observed in NCs than ethanol extract (EE) (under UV-vis light treatment) and higher carotenoids retention (\%) was observed in NCs compared to EE and data already published on the stability of non-encapsulated carotenoids (under thermal treatment). In addition, NCs when exposed to UV-vis light treatment had higher activation energy and lower constant rate $(k)$ than EE. In conclusion, nanoencapsulation offers greater stability to the $\beta$-carotene, $\alpha$-carotene, and lutein upon exposure to conditions similar to those used in the food processing (heat) and storage (UV-vis light).

( 2017 Institution of Chemical Engineers. Published by Elsevier B.V. All rights reserved.
\end{abstract}

\section{Introduction}

Carotenoids-the pigments biosynthesized by photosynthetic bacteria, algae, and higher plants-are responsible for the plant color that ranges from light yellow to deep red. Although animals cannot synthesize carotenoids de novo, they assimilate these compounds through various dietary sources (Namitha and Negi, 2010). An appropriate consumption of a variety of fruits and vegetables rich in carotenoids sufficiently supply these compounds to the animals (Khoo et al., 2011). For example, carrots are important sources of major carotenoids such as $\beta$-carotene, $\alpha$-carotene, and lutein (Maurer et al., 2014).

Structural analyses have classified $\beta$-carotene and $\alpha$-carotene as carotenes and lutein as a xanthophyll. $\beta$-Carotene and $\alpha$-carotene possess hydrocarbon chains in the absence of oxygen, whereas lutein is an

\footnotetext{
* Corresponding author. Fax: +55 5133087048 .

E-mail addresses: medelin.silva@rolante.ifrs.edubr (M.M. da Silva), karinapaese@gmail.com (K. Paese), silvia.guterres@ufrgs.br (S.S. Guterres), adriana.pohlmann@ufrgs.br (A.R. Pohlmann), josianekr@gmail.com (J.K. Rutz), fernando.cantillano@embrapa.br (R.F. Flores Cantillano), l.nora@me.com (L. Nora), alessandro.rios@ufrgs.br (A.d.O. Rios).

http://dx.doi.org/10.1016/j.fbp.2017.05.004

0960-3085/@ 2017 Institution of Chemical Engineers. Published by Elsevier B.V. All rights reserved.
} 
oxygenated compound derivative of carotenes (Pogson et al., 1996). Due to their chemical structure and interaction with biological membranes in the human body, carotenoids have antioxidant properties (Gammone et al., 2015). Owing to the presence of double bonds in their chemical structure, they can scavenge and quench free radicals, such as reactive species of oxygen and nitrogen (Polyakov et al., 2001).

In general, the consumption of carotenoids is associated with decreased risk of various types of cancers (Lu et al., 2015; Wang et al., 2015; Zu et al., 2014) and cardiovascular disease (Bhupathiraju et al., 2013). In addition of possessing antioxidant activities, $\beta$-carotene and $\alpha$-carotene have pro-vitamin A activity due to the presence of terminal $\beta$-ionone ring (Kopec et al., 2014). In contrast, lutein, found in human ocular tissues (Khachik et al., 2002), do not possess pro-vitamin A activity. Lutein is one of the major carotenoids involved in the protection against age-related macular degeneration development (Wu et al., 2015).

Carotenoids can be used as effective replacements for synthetic colorants added to food products as these compounds are more accepted by consumers (De Paz et al., 2013). However, drawbacks such as their hydrophobic nature and instability at high temperatures, in light, and with oxygen and other chemical components (Lerfall, 2016) hamper their successful application in food matrices (Campardelli et al., 2012), particularly in water-rich foods.

A previous study (Giménez et al., 2015) monitored the color degradation of natural yellow colorants that are used in foods (such as lutein, $\beta$-carotene, curcumin, riboflavin, gardenia yellow, and Opuntia extract) under varying heat treatment $\left(30,50,70\right.$, and $\left.90^{\circ} \mathrm{C}\right)$ for $6 \mathrm{~h}$. According to this study, the rate of color degradation increased with the increasing temperature in all cases. Therefore, some colorants such as free carotenoids are unstable when subjected to heat treatments, even if the temperature is $<100^{\circ} \mathrm{C}$. Furthermore, Spada et al. (2012) examined the kinetics parameters of $\beta$-carotene degradation when exposed and unexposed to UV-vis light and reported that the rate constant $\left(k /\right.$ days $\left.^{-1}\right)$ of $\beta$-carotene stored at $25^{\circ} \mathrm{C}$ under UV-vis light was higher $(0.136 \pm 0.007)$ than that of $\beta$-carotene stored at $25^{\circ} \mathrm{C}$ in the dark $(0.069 \pm 0.003)$. This may be attributed to the formation of singlet oxygen through the biological compounds in the presence of light (Yahia and Ornelas-Paz, 2010). Subsequently, the singlet oxygen binds with the hydrocarbon chain of carotenoids, leading to its degradation.

Alternatively, nanotechnology can be applied, involving the development and application of nanometric structures in the field of food technology. These nanomaterials are of natural, incidental or manufactured origin and are defined as a system that should consist for $50 \%$ or more of particles (number distribution) having a size between 1-100 nm (Official Journal of the European Union, 2011). Nanotechnology offers easy applicability of compounds with poor water solubility in food matrices. Furthermore, it improves the thermal and UV-vis light stability, oral bioavailability, sensory attributes, and physiological performance of functional food ingredients (Huang et al., 2010).

Various conditions during food processing and storage may interfere with the nanoencapsulated carotenoid stability; however, the extent of interference is lower than that during free carotenoids degradation. Lobato et al. (2015) produced nanoencapsulated bixin by interfacial deposition of the preformed polymer technique, and observed that non-nanoencapsulated bixin (free bixin) degraded before than nanoencapsulated bixin. The rate constants $(k)$ of nonnanoencapsulated bixin is higher when compared to rate constants $(k)$ of nanoencapsulated bixin at all the tested temperatures $(65,80$, and $\left.95^{\circ} \mathrm{C}\right)$.

Recently, much attention has been focused on studying the thermal and UV-vis light stability kinetics of the nanoencapsulated carotenoids (Anarjan and Tan, 2013; Chen et al., 2014); however, only nanoencapsulated compounds in their individual form have been studies thus far. Therefore, this study aimed to study the stability of conanoencapsulated carotenoids (blend of $\beta$-carotene, $\alpha$-carotene, and lutein) in lipid-core nanocapsules (LNC) under different industrial treatments such as thermal and UV-light treatment.

\section{Material and methods}

\subsection{Materials}

The poly- $\varepsilon$-caprolactone polymer (PCL) $(\mathrm{Mw}=80,000)$, used for wall material composition of the LNC, and sorbitan monostearate (Span 60) were purchased from Sigma (St. Louis, MO, USA). Capric/caprylic triglycerides (CCTs) and polysorbate 80 (Tween 80) were purchased from Delaware (Porto Alegre, Brazil). All other chemicals and solvents were of analytic or pharmaceutical grade. The vegetal material ('Baltimore' carrots) was obtained from Vacaria, Rio Grande do Sul, Brazil $\left(28^{\circ} 30^{\prime} 44^{\prime \prime} \mathrm{S}\right.$ to $\left.50^{\circ} 56^{\prime} 02^{\prime \prime} \mathrm{W}\right)$.

\subsection{Obtaining ethanol extract containing carotenoids}

$\beta$-Carotene, $\alpha$-carotene, and lutein were extracted from 'Baltimore' carrots $(1 \mathrm{~g})$ using the absolute ethanol as the extractor solvent ( $\geq 99.5 \%$ ) at $25^{\circ} \mathrm{C}$ for $55 \mathrm{~min}$ using four extractions and $40 \mathrm{~mL}$ of absolute ethanol for each extraction. The carotenoids profile of the ethanol extract (EE) was performed using highperformance liquid chromatography (HPLC).

\subsection{Preparation of LNC}

The LNC were prepared from a blend of carotenoids ( $\beta$ carotene, $\alpha$-carotene and lutein; NCs) by interfacial deposition of the preformed polymer technique according to Venturini et al. (2011), with some modifications in the amounts of acetone and ethanol. The LNC are composed of two phases, an organic and aqueous phase. PCL (250 mg), Span 60 (95 mg), CCTs $(400 \mu \mathrm{L})$, acetone $(135 \mathrm{~mL}), \mathrm{EE}(15 \mathrm{~mL})$ of $\beta$-carotene, $\alpha$ carotene, and lutein from 'Baltimore' carrots were used for the organic phase of the NCs. The EE amount was established so that the final formulation of the NCs possessed a concentration of $26 \mu \mathrm{g} / \mathrm{mL}$ of the sum of carotenoids ( $\beta$-carotene, $\alpha$-carotene and lutein).

In the aqueous phase, Tween $80(192.50 \mathrm{mg})$ and ultrapure water $(132.50 \mathrm{~mL})$ were used. The organic and aqueous phases were magnetically stirred for $40 \mathrm{~min}$ at $40^{\circ} \mathrm{C}$ and $25^{\circ} \mathrm{C}$, respectively, until complete dissolution of materials. Subsequently, the organic phase was injectedinto the aqueous phase with stirring for $10 \mathrm{~min}$ at $25^{\circ} \mathrm{C}$. The NCs formulation was concentrated under reduced pressure to a final volume of $25 \mathrm{~mL}$.

\subsection{NCs characterization}

\subsubsection{Hydrogen potential $(\mathrm{pH})$}

A potentiometer (Quimis ${ }^{\circledR}, \mathrm{Q} 400 \mathrm{~A}$, Diadema, São Paulo) was used to determine $\mathrm{pH}$ of the NCs and EE at $25^{\circ} \mathrm{C}$.

\subsubsection{Mean diameter}

The mean diameter and span values (Eq. (1)) of the NCs were calculated by laser diffraction (LD; volume-weighted mean diameter; $\mathrm{D}_{4,3}$ ) using Mastersizer $2000^{\circledR}$ (Malvern Instruments, UK). The refractive indexes used for the PCL and water were 1.54 and 1.33, respectively. In addition, the mean diameter was analyzed by dynamic light scattering (DLS; z-average) using Zetasizer ${ }^{\circledR}$ nano-ZS (Malvern Instruments, UK). To determine the $z$-average of the NCs, the sample dilutions were performed with pre-filtered MilliQ ${ }^{\circledR}$ water $(0.45 \mu \mathrm{m})$. The dynamic light 
scattering provides parallel to the average particle diameter (z-average) the polydispersity index (PDI) of the NCs.

Span value : $\frac{d_{0.9}-d_{0.1}}{d_{0.5}}$

\subsubsection{Zeta potential}

The electrophoretic mobility (Zetasizer ${ }^{\circledR}$ nano-ZS, Malvern, $\mathrm{UK}$ ) was used to determine the zeta potential values of the NCs formulation. The samples were previously diluted in a pre-filtered $(0.45 \mu \mathrm{m})$ aqueous solution $(10 \mathrm{mM} \mathrm{NaCl})$.

\subsubsection{HPLC analysis}

HPLC analysis was performed using Agilent series 1100 (Santa Clara, CA, USA) with a C30 polymeric column YCM $(250 \times 4.6 \mathrm{~mm}$ i.d.; $3-\mu \mathrm{m}$ particle size $)$ at $33^{\circ} \mathrm{C}$. Data were acquired and processed using the ChemStation ${ }^{\circledR}$ software. The mobile phase gradient consisted of water, methanol, and methyl tert-butyl ether at a flow rate of $1 \mathrm{~mL} / \mathrm{min}$ and injection volume was $5 \mu \mathrm{L}$. The chromatographs were processed at an absorption wavelength of $470 \mathrm{~nm}$. Moreover, a calibration curve with a determination coefficient $\left(r^{2}\right)>0.99$ was used to quantify $\beta$-carotene, $\alpha$-carotene, and lutein.

Prior to their injection in the HPLC, the samples were filtered with a modified PTFE membrane $(0.45 \mu \mathrm{m})$ for aqueous and organic solvents (Millipore, Barueri, SP, Brazil). All the solvents used in the HPLC were of chromatographic grade and were previously filtered through a Millipore vacuum filtration system using a $0.22 \mu \mathrm{m}$ membrane for organic solvents (Millipore, Barueri, SP, Brazil).

The total retention of carotenoids in the NCs and aqueous phase of NCs were used to calculate the encapsulation efficiency (EnEf; Eq. (2)) of the nanometric suspension. To evaluate the total retention of carotenoids in the LNC, $\beta$-carotene, $\alpha$ carotene, and lutein were extracted from the NCs using $500 \mu \mathrm{L}$ of NCs and $2.5 \mathrm{~mL}$ of acetonitrile (Lobato et al., 2013; Venturini et al., 2011). This mixture was sonicated for $30 \mathrm{~min}$, dried in compressed $\mathrm{N}_{2}$, diluted with methyl tert-butyl ether $(1 \mathrm{~mL})$, and finally injected in the HPLC. To obtain the carotenoid content in the aqueous phase of NCs, the filtrate was injected into the HPLC. This filtrate was obtained by the ultrafiltration (Ultracel YM-100, cut-off of $10 \mathrm{kDa}$; Amicon ${ }^{\circledR}$ Millipore Corporation, United States) and centrifugation $(15 \mathrm{~min}$ at $1690 \times \mathrm{g})$ of an aliquot of NCs $(400 \mu \mathrm{L})$. Thus, the encapsulation efficiency value was determined as follows: stirred in a water bath for $0,30,50,70,100,140$, and $180 \mathrm{~min}$ in the dark. After each period of heating at 70,80 , and $90^{\circ} \mathrm{C}$, the samples were cooled in an ice bath. The $\beta$-carotene, $\alpha$ carotene, and lutein retention was measured by HPLC and was used to determinate the kinetics parameters using SigmaPlot 12.0 software.

\subsection{NCs and EE stability under UV-vis light and different temperatures}

The total retention of carotenoids was used as evaluation parameter for the photostability (UV-vis light) of NCs $(26 \mu \mathrm{g} / \mathrm{mL})$ and EE $(26 \mu \mathrm{g} / \mathrm{mL})$ under different temperatures (5, 15 , and $\left.25^{\circ} \mathrm{C}\right)$ and time intervals $(0,5,10,35$, and $50 \mathrm{~h})$. The triplicates of the samples (NCs and EE) were conditioned in glass test tubes hermetically sealed, which prevented the oxygen interference on carotenoid degradation. These test tubes containing the samples (NCs and EE) were placed in a chamber and on magnetic stirrers, which ensured the UV-vis light irradiation of the whole sample. The storage temperatures and the irradiation of the samples were controlled using a refrigerator system and four $9 \mathrm{~W}$ white lamps (3400lm; 4600 lux; external structure of glass; $26 \times 604 \mathrm{~mm}$ ), respectively. The $\beta$ carotene, $\alpha$-carotene, and lutein retention was analyzed by HPLC and was used to determinate the kinetic parameters using SigmaPlot 12.0 software.

\subsection{Experimental design and statistical analysis}

The NCs and EE formulations were performed in triplicate and the experimental design was completely randomized. The results of carotenoids retention during thermal and UV-vis light treatment was reported in graphics (SigmaPlot 12.0 software), represented by mean and standard deviation of triplicates. While $k$ and Ea (activation energy) were calculated, respectively, through the Excel ${ }^{\circledR}$ software 2013 and the Arrhenius equation (Eq. (3)).

$k=\mathrm{A} e^{\frac{-E a}{R T}}$

where $k$ (reaction constant), A (constant of Arrhenius equation), Ea (activation energy; kJ/mol), R (universal constant of gases; $8.3144 \mathrm{~J} / \mathrm{mol} / \mathrm{K}$ ) and $\mathrm{T}$ (absolute temperature; ${ }^{\circ} \mathrm{K}$ ).

$\operatorname{EnEf}(\%)=\frac{\text { Total carotenoids of NCs }- \text { Carotenoids in the aqueous phase of NCs }}{\text { Total carotenoids of NCs }} \times 100$

\subsubsection{Log D (logarithm of the distribution coefficient)}

The chemical structure of samples and the medium $\mathrm{pH}$ are used to determine the $\log \mathrm{D}$, through the software ACD Log D 6.0 (Advanced Chemistry Development, Inc., Toronto, Canada). The $\log \mathrm{D}$ value allows to estimate the lipophilicity of the observed compound (Oliveira et al., 2013).

\subsection{NCs stability under thermal treatment in the dark}

The total retention of carotenoids was used as a parameter to analyze the thermal stability of the NCs $(26 \mu \mathrm{g} / \mathrm{mL})$ and EE. $(26 \mu \mathrm{g} / \mathrm{mL})$. Aliquots $(600 \mu \mathrm{L})$ of the NCs and EE were entrapped in different Eppendorf tubes and maintained at distinct temperatures ( $\mathrm{NCs}-70,80$, and $90^{\circ} \mathrm{C}$; $\mathrm{EE}-70^{\circ} \mathrm{C}$ ) and

\section{Results and discussion}

\subsection{NCs characterization}

During the characterization of NCs suspension, the carotenoids ( $\beta$-carotene, $\alpha$-carotene, and lutein) added to the formulation were localized in the nanocapsules core because of the $100 \%$ encapsulation efficiency. The total retention of carotenoids in the NCs and aqueous phase of NCs were $25.62 \mu \mathrm{g} / \mathrm{mL}$ and $0 \mu \mathrm{g} / \mathrm{mL}$, respectively, which provided an encapsulation efficiency of $100 \%$. Ourique et al. (2008) evaluated the physicochemical characterization of retinoic acid-loaded nanocapsules, prepared by interfacial deposition of the preformed polymer with poly- $\varepsilon$-caprolactone as the wall material and two different oily phases (capric/caprylic triglycerides; sunflower seed oil), and observed high encap- 

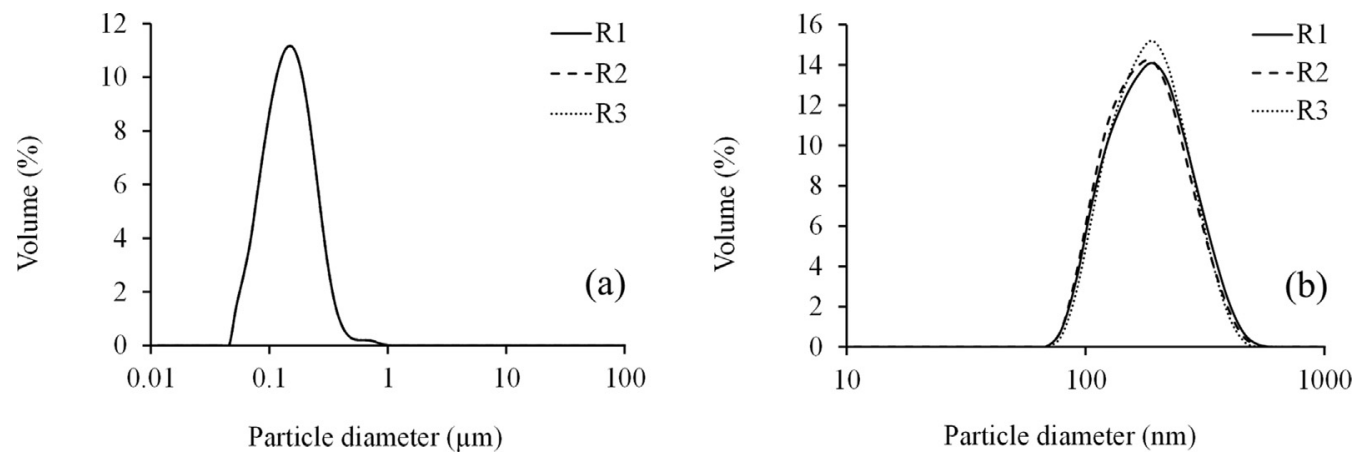

Fig. 1 - Behavior of the NCs particle size distribution using both the diameter techniques (LD and DLS).

sulation efficiency (>99.90\%). The method, to produce the nanocapsules, proposed in this study and the recently mentioned provide high encapsulation efficiency of approximately 100\% (Venturini et al., 2011).

The pH of the NCs and EE formulation was $3.21 \pm 0.04$ and $3.57 \pm 0.08$ (apparent $\mathrm{pH}$ ), respectively. The $\mathrm{pH}$ of the NCs formulation obtained in this study was lower than that reported in other studies (Frozza et al., 2010; Santos et al., 2015; Siqueira et al., 2011). One possible reason for this may be the extraction of other compounds such as flavonoids during the ethanolic extraction of carotenoids, influencing the $\mathrm{pH}$ value of the extract. Since several studies report the existence of flavonoids as catechin and epicatechin in different genotypes of carrot (Bozalan and Karadeniz, 2011; Rakcejeva et al., 2012).

The particle size distribution demonstrated monomodal behavior in both the diameter techniques (LD and DLS), as shown in Fig. 1. The mean diameter of the NCs using the LD (volume-weighted mean diameter; $\mathrm{D}_{4,3}$ ) and DLS ( $\mathrm{z}$ average) were $151.33 \pm 5.03$ and $180.30 \pm 0.70 \mathrm{~nm}$, respectively. This is consistent with other studies using the same technique (Mazzarino et al., 2012; Rigo et al., 2014; Santos et al., 2015).

The interfacial deposition of the preformed polymer method, known as nanoprecipitation, is suitable for the nanosuspension production with a monomodal particle size distribution (Mora-Huertas et al., 2010). The monomodal behavior of the particle size distribution is important because it confirms the absence of micrometric size particles in the nanocapsule suspension. The span and PDI values were $1.37 \pm 0.10$ and $0.1 \pm 0.03$, respectively, demonstrating a high degree of NCs homogeneity.

The $\log \mathrm{D}$ values were 15.51 ( $\beta$-carotene), 15.46 ( $\alpha$-carotene) and 11.78 (lutein). Oliveira et al. (2013) report that compounds with a $\log \mathrm{D}$ higher than 2.0 are poorly soluble in water. Based on this information we can assert that all the carotenoids added to the formulation are located in the nanocapsules core.

Thus, the results mentioned above demonstrate that it was possible to produce nanocapsules with the core loaded by a blend of carotenoids ( $\beta$-carotene, $\alpha$-carotene, and lutein) through the interfacial deposition of the preformed polymer (PCL).

Of the various studies investigating the zeta potential value of the distinct nanoparticle suspensions, the study by ZanottoFilho et al. (2013) produced lipid-core nanocapsules loaded with curcumin using PCL (wall material) and polysorbate 80 (surfactant) by interfacial deposition of preformed polymer, and obtained zeta potential values of $-9.56 \pm 0.66$. These values in module are lower than that found in our study $(-22.66 \pm 0.52)$, probably due to the extraction of other compounds in the EE of carotenoids; these can be located at the particle/water interface, thereby altering the zeta potential.
Thus, the EE that finally formed the nanocapsules' core was one of the responsible factors for suspension charge, which is represented by the zeta potential. In relation to the other factors that exert influence on the zeta potential, according to Mora-Huertas et al. (2012) we can indicate composition and pH of the aqueous phase. According to a study published by Desu et al. (2013), the NCs formulation was physically stable because of Tween 80 (nonionic surfactant) presence, which provides a minimal sedimentation of the dispersion through steric hindrance of particle interactions, preventing flocculation.

The NCs characterizing parameters corroborate the results found by Silva et al. (2016). This work, produced by the same research group from the current manuscript, was essential for further investigations.

\subsection{NCs stability under thermal treatment in the dark}

Fig. 2 (Mean \pm standard deviation; the standard deviations are not visible, since they are very low) shows the retention of carotenoids ( $\beta$-carotene, $\alpha$-carotene, and lutein) in the NCs and EE under thermal treatment $\left(70,80\right.$, and $\left.90^{\circ} \mathrm{C}\right)$. The thermal stability kinetics of $\beta$-carotene, $\alpha$-carotene, and lutein in nanoencapsulated and free form were fitted to first-order kinetics with a determination coefficient $\mathrm{r}^{2}>0.82$ and $\mathrm{r}^{2}>0.88$ respectively. In general, thermal degradation of carotenoids follows a first-order reaction (Knockaert et al., 2012; Lim et al., 2014; Saxena et al., 2012; Zepka et al., 2009).

Fig. 2 shows that the rate of carotenoid ( $\beta$-carotene, $\alpha$ carotene, and lutein) retention decreased with the increase in incubation time at 70 (NCs and EE), 80 (NCs), and $90^{\circ} \mathrm{C}$ (NCs) and with the increase of incubation temperature (NCs). This result is consistent with that reported by Sáiz-Abajo et al. (2013), which aimed to evaluate the protective effect of casein nanomicellar structure against thermal degradation of the encapsulated $\beta$-carotene. They observed that longer periods of heat exposure provided higher rates of $\beta$-carotene degradation because the loss of encapsulated $\beta$-carotene in casein micelles were $30.90 \%\left(8 \mathrm{~h}\right.$ at $\left.80^{\circ} \mathrm{C}\right)$ and $14.10 \%\left(0.5 \mathrm{~h}\right.$ at $\left.80^{\circ} \mathrm{C}\right)$.

A nanoencapsulated $\beta$-carotene system with PCL polymer provides higher thermal protection to the bioactive compound than the non-encapsulated $\beta$-carotene system, affirming that the nanoencapsulated compound system decreases the required amount of substance that must be added during the development of a thermally processed food product (González-Reza et al., 2015). This lower degradation of encapsulated bioactive compounds was observed in the present study, since at $70^{\circ} \mathrm{C}$ there was a $\beta$-carotene retention of $73.34 \pm 0.32 \%$ (nanoencapsulated form) and $31.64 \pm 0.04 \%$ (free form); $\alpha$-carotene retention of $66.37 \pm 0.20 \%$ (nanoencapsulated form) and $26.68 \pm 0.07 \%$ (free form); lutein retention of 

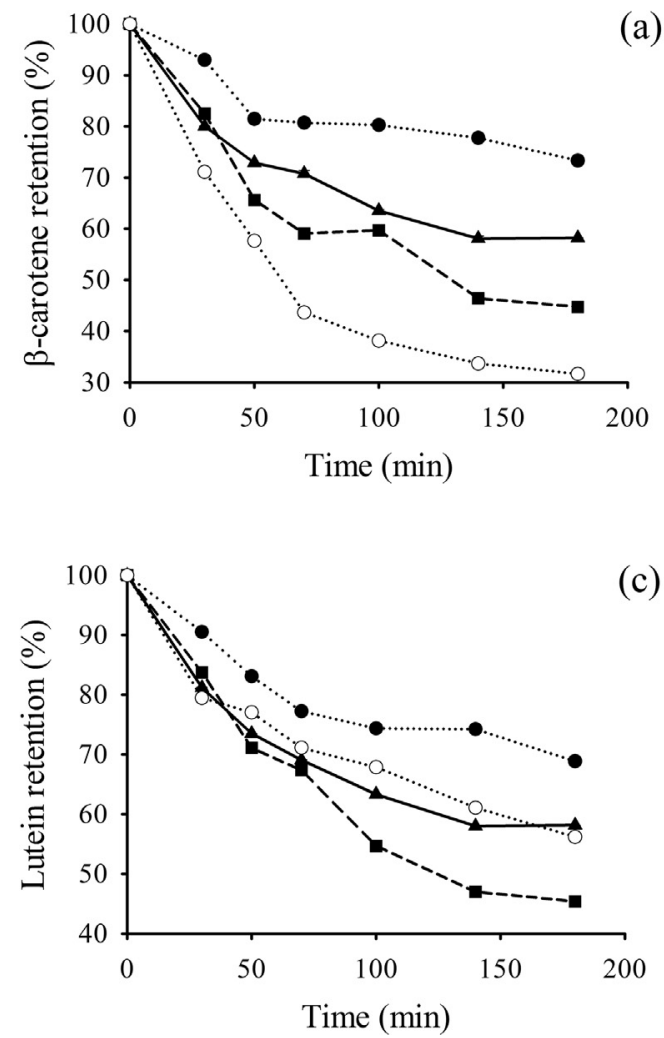

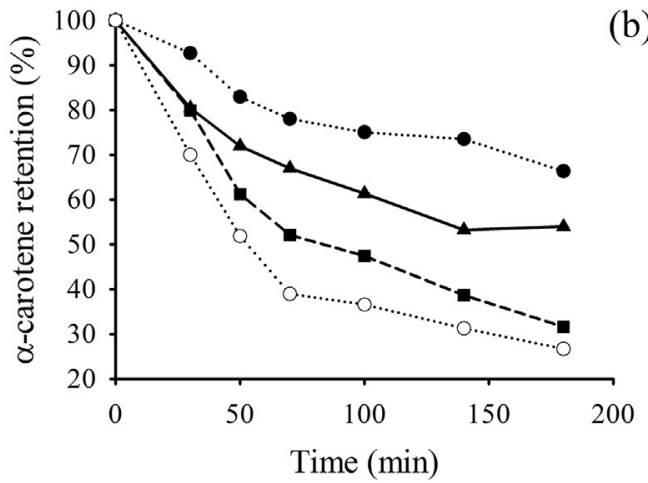

(b)

)

Fig. 2 - Total retention of carotenoids during thermal treatment $\left(70,80\right.$, and $\left.90^{\circ} \mathrm{C}\right)$ of the NCs and EE for $180 \mathrm{~min}$ in the dark.

\section{Table 1 - Rate constants $(k)$ and activation energy $(\mathrm{Ea})$ values of degradation kinetics of carotenoids ( $\beta$-carotene, $\alpha$-carotene, and lutein) contained in the NCs and EE during thermal treatment $\left(70,80\right.$ and $\left.90^{\circ} \mathrm{C}\right)$ for $180 \mathrm{~min}$ in the dark.}

Carotenoid Rate constants $k \times 10^{-3}\left(\mathrm{~min}^{-1}\right)$ Ea $\left(\mathrm{kJ} \mathrm{mol}^{-1}\right)$

Free $\beta$-carotene
Nanoencapsulated $\beta$-carotene
Free $\alpha$-carotene
Nanoencapsulated $\alpha$-carotene
Free lutein
Nanoencapsulated lutein

$68.87 \pm 0.03 \%$ (nanoencapsulated form) and $56.19 \pm 0.03 \%$ (free form) (Fig. 2).

The higher temperatures lead to greater carotenoid losses because of carotenoids degradation due the formation of isomerization (trans-cis) and/or oxidation products as well as volatile and low molecular weight compounds that cannot be detected by HPLC (Zepka et al., 2009).

Carotenoid loss under heating occurs concomitantly with the formation of isomers and directly depends on the food system, carotenoid type, and applied temperature (Achir et al., 2010; Hwang et al., 2012). During the thermal treatment of trans- $\beta$-carotene, some isomers, such as 9-cis-, 13-cis-, and 15-cis- $\beta$-carotene, are formed (Ribeiro and Oliveira, 2013). Moreover, Tang and Chen (2000) measured the stability of freeze-dried carotenoid powder extracted from carrot pulp during dark storage at 4,25 , and $45^{\circ} \mathrm{C}$ and found the presence of isomers. Under the previously described conditions, 13 -cis- $\beta$-carotene, 15 -cis- $\beta$-carotene, 9cis- $\beta$-carotene, and 13,15-di-cis- $\beta$-carotene were formed from all-trans- $\beta$-carotene; 13 -cis- $\alpha$-carotene, 9-cis- $\alpha$-carotene, 15 cis- $\alpha$-carotene were formed from all-trans- $\alpha$-carotene; and 9-cis-lutein and 13-cis-lutein were formed from all-translutein. Therefore, trans-cis isomerization causes the color

$80^{\circ} \mathrm{C} \quad 90^{\circ} \mathrm{C}$

2.9

3.4

3.4

2.9

4.4
-
6.2
-
4.6

54.77

55.19

44.81 changes in heat-treated food products. In addition, the isomerization reaction alter the biological properties of carotenoids, leading to reduced pro-vitamin A activity and antioxidant capacity (Schieber and Carle, 2005).

Table 1 shows the $k$ and Ea during the degradation of $\beta$-carotene, $\alpha$-carotene, and lutein in the nanoencapsulated and free form under thermal treatment $\left(70,80\right.$, and $\left.90^{\circ} \mathrm{C}\right)$ for $180 \mathrm{~min}$. These kinetic parameters provide useful information on the changes in the food quality occurring during thermal processing (Ahmed et al., 2002). The degradation rate constants $(k)$ quantifies the speed of a chemical reaction, while the activation energy is the lower energy required for a chemical reaction to occur.

Comparing the three carotenoids ( $\beta$-carotene, $\alpha$-carotene and lutein; free and nanoencapsulated form) at $70^{\circ} \mathrm{C}$, a higher thermal degradation rate constant $(k)$ was observed when these compounds were free (Table 1). This demonstrates that the degradation of $\beta$-carotene, $\alpha$-carotene and lutein occurs more rapidly when they are unprotected (free).

In addition, compared to other carotenoids, nanoencapsulated lutein has lower activation energy (Ea) (Table 1). This result is in agreement with that reported by Henry et al. (1998) who evaluated the thermal degradation kinetics of 

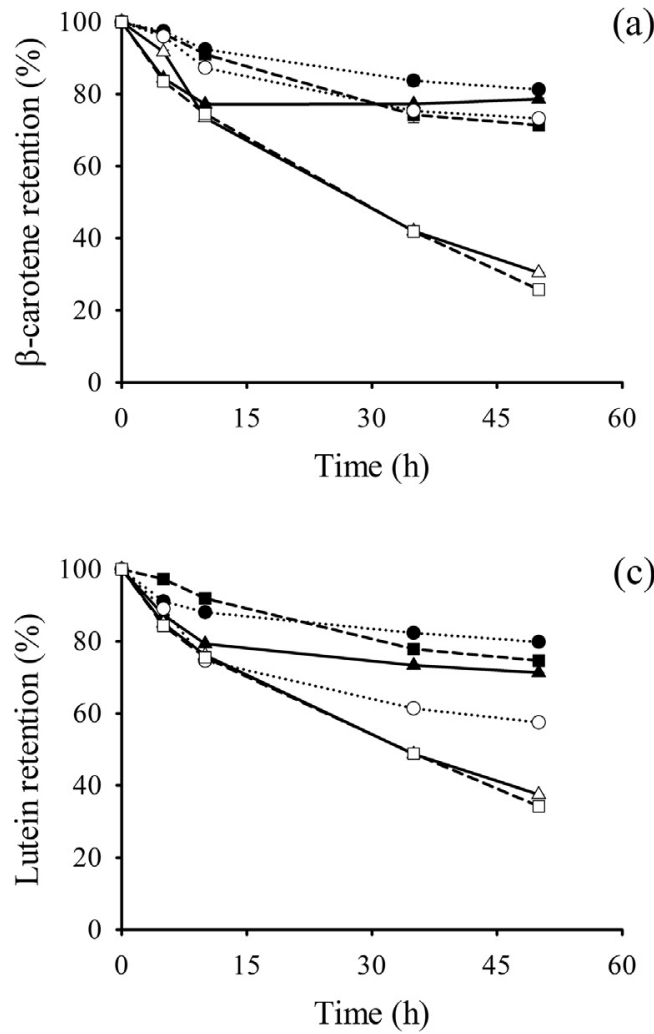

c)

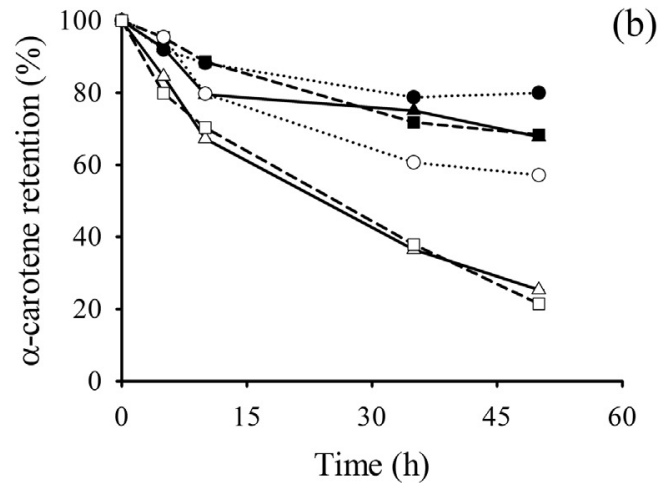

(b)

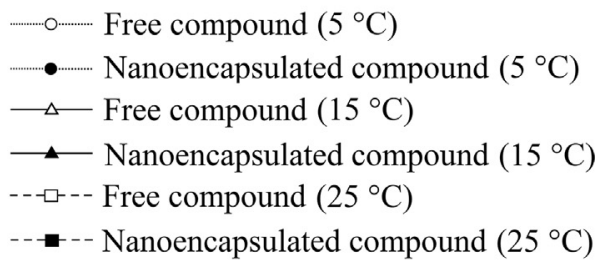

Fig. 3 - Total retention of carotenoids in the NCs and EE during UV-visible light treatment $\left(5,15\right.$, and $\left.25^{\circ} \mathrm{C}\right)$ for $50 \mathrm{~h}$.

carotenoids in safflower seed oil at 75,85 , and $95^{\circ} \mathrm{C}$ and found that the Ea value for lutein and $\beta$-carotene was 104.18 and $109.62 \mathrm{~kJ} \mathrm{~mol}^{-1}$, respectively. The hydroxyl groups present in the chemical structure of lutein form bonds with the polymeric wall material leading to easier lutein degradation when compared to other carotenoids.

A previous study (Giménez et al., 2015) on the thermal degradation kinetics $\left(30,50,70\right.$, and $90^{\circ} \mathrm{C}$ ) during $6 \mathrm{~h}$ of natural yellow colorants in a model system (ethanol:water; 3:2; v/v) obtained by $\beta$-carotene and lutein revealed Ea values of $6.49 \mathrm{~kJ} \mathrm{~mol}^{-1}$ and $3.18 \mathrm{~kJ} \mathrm{~mol}^{-1}$, respectively. The Ea values were $54.77 \mathrm{~kJ} \mathrm{~mol}^{-1}$ for $\beta$-carotene and $44.81 \mathrm{~kJ} \mathrm{~mol}^{-1}$ for lutein; these values are higher than those reported by Giménez et al. (2015) for free $\beta$-carotene and lutein. Lobato et al. (2015) reported that the Ea value of nanoencapsulated bixin $\left(99.62 \mathrm{~kJ} \mathrm{~mol}^{-1}\right)$ was higher than that of free bixin $\left(63.01 \mathrm{~kJ} \mathrm{~mol}^{-1}\right)$ at temperatures of 65,80 , and $95^{\circ} \mathrm{C}$ for $125 \mathrm{~min}$. Therefore, nanoencapsulation protects the compounds entrapped in the nanocapsules core. According to González-Reza et al. (2015), this protection capability of nanoparticles is attributed to the presence of poly- $\varepsilon$ caprolactone polymer in the wall.

However, the Ea values strongly depend on the experimental conditions. For example, Hadjal et al. (2013) studied the thermal degradation kinetics of the lutein from blood orange in different models and real food systems at $67.5^{\circ} \mathrm{C}$ and reported the following Ea values: real juice $\left(65.02 \mathrm{~kJ} \mathrm{~mol}^{-1}\right)$, model system 1 (esterified form; $\mathrm{pH} 3.5 ; 88.24 \mathrm{~kJ} \mathrm{~mol}^{-1}$ ), model system 2 (free form; $\mathrm{pH} 3.5 ; 98.28 \mathrm{~kJ} \mathrm{~mol}^{-1}$ ), and model system 3 (free form; pH 7.0; $60.08 \mathrm{~kJ} \mathrm{~mol}^{-1}$ ).

The thermal degradation rate constants of nanoencapsulated $\beta$-carotene, $\alpha$-carotene, and lutein increased concurrently with the increase in incubation temperature (Table 1). This behavior was also observed by Aparicio-Ruiz et al. (2011), who investigated the thermal degradation kinetics of lutein, $\beta$-carotene, and $\beta$-cryptoxanthin by incubating virgin olive oils at $60^{\circ} \mathrm{C}(744 \mathrm{~h}), 80^{\circ} \mathrm{C}(370 \mathrm{~h}), 100^{\circ} \mathrm{C}(64 \mathrm{~h})$, and $120^{\circ} \mathrm{C}$ $(42 \mathrm{~h})$. This trend was expected because higher temperatures lead to higher degradation and oxidation of the carotenoids (Lai et al., 2012).

The degradation kinetics rate constant $(k)$ of the $\beta$-carotene at $80^{\circ} \mathrm{C}$ was $2.9 \times 10^{-3} \mathrm{~min}^{-1}$ (Table 1). However, a recent study (Chen and Zhong, 2015) evaluating the thermal stability of $\beta$-carotene $(0.1 \%)$ dissolved in peppermint oil (3\%) microemulsified by Tween $20(20 \%)$ obtained a rate constant (k) of $22.94 \times 10^{-3} \mathrm{~min}^{-1}$ at $80^{\circ} \mathrm{C}$. The higher rate constant $(k)$ is probably due to the lack of polymeric wall in the emulsion systems.

The retention of carotenoids after $30 \mathrm{~min}$ at $90^{\circ} \mathrm{C}$ in the NCs was $82.51 \pm 0.03$ ( $\beta$-carotene), $79.90 \pm 0.04$ ( $\alpha$-carotene), and $83.73 \pm 0.03$ (lutein); approximately only $20 \%$ of all the three compounds was lost. Therefore, NCs can be applied in food matrices that are thermally treated, for example, through the pasteurization.

\subsection{NCs and EE stability under UV-vis light and different temperatures}

Fig. 3 (Mean \pm standard deviation; the standard deviations are not visible, since they are very low) shows the UV-vis light stability kinetics of the carotenoids contained in the NCs and EE. Similar to the thermal degradation, the UV-vis light stability kinetics was adjusted to a first-order reaction with a determination coefficient $\mathrm{r}^{2}$ above 0.94 (NCs) and 0.82 (EE) for the three carotenoids. In general, the luminous degradation kinetics of the carotenoids, such as $\beta$-carotene and lycopene, follow a first-order model (Calvo and Santa-María, 2008; Chen and Huang, 1998).

During the UV-vis light treatment at three different temperatures $\left(5,15\right.$, and $\left.25^{\circ} \mathrm{C}\right)$, a decrease of the carotenoid 
Table 2 - Rate constants $(k)$ and activation energy $(E a)$ values of degradation kinetics of carotenoids ( $\beta$-carotene, $\alpha$-carotene, and lutein) contained in the NCs and EE during UV-vis light treatment $\left(5,15\right.$, and $\left.25{ }^{\circ} \mathrm{C}\right)$ for $50 \mathrm{~h}$.

Carotenoid

Rate constants $k \times 10^{-3}\left(\mathrm{~min}^{-1}\right)$

Ea $\left(\mathrm{kJ} \mathrm{mol}^{-1}\right)$

5

Free $\beta$-carotene

$15^{\circ} \mathrm{C}$

$25^{\circ} \mathrm{C}$

Nanoencapsulated $\beta$-carotene

Free $\alpha$-carotene

20.2

9.2

2.1

11.5

Nanoencapsulated $\alpha$-carotene

Free lutein

2.1

Nanoencapsulated lutein

10.3

4.1

26.9

26.0

( $\beta$-carotene, $\alpha$-carotene and lutein) retention (\%) was observed in the NCs and EE (Fig. 3). For example, compared to the initial amount of carotenoids (100\%), the remaining amount of $\beta$-carotene, $\alpha$-carotene, and lutein at $25^{\circ} \mathrm{C}$ after $50 \mathrm{~h}$ was $71.41 \pm 1.09(\mathrm{NCs})$ and $25.79 \pm 0.12(\mathrm{EE}), 68.34 \pm 0.62$ (NCs) and $21.48 \pm 0.13(\mathrm{EE}), 74.64 \pm 0.04(\mathrm{NCs})$ and $34.27 \pm 0.03$ (EE), respectively. In addition, this behavior was observed during the photo-dependent treatment of other carotenoid ( $\beta$-cryptoxanthin), decreasing approximately $90 \%$ of its content after $24 \mathrm{~h}$ of incubation in hexane at $25^{\circ} \mathrm{C}$ due to the light-induced oxidation and isomerization (Li et al., 2015). According to Chen et al. (1994), during UV-vis light treatment of $\beta$-carotene and $\alpha$-carotene in a model system (hexane) with catalyst (iodine) at $25^{\circ} \mathrm{C}$, the isomer such as 13,15 -di-cis$\beta$-carotene and 9-cis- $\alpha$-carotene and 13 -cis- $\alpha$-carotene were formed from all-trans- $\beta$-carotene and all-trans- $\alpha$-carotene, respectively.

The carotenoid ( $\beta$-carotene, $\alpha$-carotene, and lutein) retention was higher in the NCs than in EE, regardless of the temperature and the storage time (Fig. 3), reaffirming that nanoencapsulation is an effective alternative for preservation of these bioactive compounds. Furthermore, this technique allows a greater maintenance of carotenoids during storage under light conditions.

Ourique et al. (2008) used tretinoin as the active compound in a nano-size system and verified the importance of a polymer in the nanometric system composition to prevent tretinoin photodegradation after $1 \mathrm{~h}$ of exposure at an artificial UV lamp (Phillips TUV lamp-UVC long life, $30 \mathrm{~W}$ ). The photodegradation rate constants $(k)$ obtained for each nanometric system were as follows: $k$ for tretinoin-loaded nanocapsules prepared with capric/caprylic triglycerides mixture was $2.87 \pm 0.14$ and sunflower seed oil was $3.03 \pm 0.44$ in the oily phase and that for tretinoin-loaded nanoemulsion prepared with capric/caprylic triglycerides mixture was $3.22 \pm 0.37$ and sunflower seed oil was $3.70 \pm 0.84$ in the oily phase. Nanocapsules of tretinoin provide higher protection against UV-induced photodegradationthan that by the nanoemulsion, independent of the oily phase composition, due to the crystallinity of the polymer that possesses the ability of reflecting and scattering UV radiation that leads to photoprotection (Jiménez et al., 2004). Wang et al. (2012) prepared lutein microcapsules by a spray drying process with porous starch and gelatin as wall material and free lutein in solution. After 30 days of exposure in day light at room temperature, the lutein retention was $89.50 \%$ in the microcapsules and $57.30 \%$ in the free lutein (Wang et al., 2012). Taken together, these studies concluded that an encapsulated compound presents higher maintenance than the free compound.

During UV-vis light treatment $\left(5,15\right.$, and $\left.25^{\circ} \mathrm{C}\right)$ for $50 \mathrm{~h}$, the rate constants $(k)$ and activation energy (Ea) values of carotenoid ( $\beta$-carotene, $\alpha$-carotene, and lutein) degradation kinetics contained in the NCs and EE are presented in Table 2. All the evaluated pigments had higher Ea in the nanoencapsulated form. Compounds with similar chemical structures, such as $\beta$-carotene and $\alpha$-carotene, showed similar Ea values, whereas lutein (encapsulated and free) exhibited the lower Ea values due to the presence of hydroxyl groups throughout their hydrocarbon chain. The results presented in Table 2 agreed well with those represent in Fig. 3, asserting that the nanoencapsulation technique can be used as one of the ways to promote the protection of bioactive compounds. Lobato et al. (2015) investigated the photo-stability kinetics of the bixin in model system of ethanol:water (2:8) in the presence of a $150 \mathrm{~W}$ filament lamp (36,000 lux) and noted that the Ea value in the nanocapsules produced with PCL $\left(48.03 \mathrm{~kJ} \mathrm{~mol}^{-1}\right)$ were higher than that in the free compound solution $\left(29.66 \mathrm{~kJ} \mathrm{~mol}^{-1}\right)$.

Minguez-Mosquera and Jaren-Galan (1995) studied the kinetics of $\beta$-carotene decoloring at different temperatures $\left(15,25,35\right.$, and $\left.45^{\circ} \mathrm{C}\right)$ and under illumination of 1000 lux in a model system (ethanol). They found that the Ea value was $57.74 \mathrm{~kJ} \mathrm{~mol}^{-1}$ and rate constant $\left(k ; \mathrm{min}^{-1}\right)$ at $25^{\circ} \mathrm{C}$ was 27.2 . This result is very similar to that observed in the present study $\left(26.0 \mathrm{~min}^{-1}\right)$, which also used ethanol.

\section{Conclusions}

The interfacial deposition of the preformed polymer technique allowed the nanocapsules production of a blend of carotenoids ( $\beta$-carotene, $\alpha$-carotene, and lutein) extracted from 'Baltimore' carrots. These nanocapsules presented a nano-size diameter. In addition, the nanometric system prepared showed a particle size distribution with monomodal behavior in both mean diameter techniques (LD and DLS), and the zeta potential suggested a high physical stability of the system during a possible storage condition. In both the conditions, thermal treatment in the dark and UV-vis light treatment under different temperatures, a first-order degradation reaction and a greater protector effect of the nanocapsules on the carotenoids stability due to the presence of polymeric wall were observed. The nanocapsules of a blend of carotenoids ( $\beta$-carotene, $\alpha$-carotene, and lutein) provide higher preservation of these compounds when compared to the EE, which allows the use of carotenoids under thermally treatment and exposure to light radiation.

\section{Acknowledgements}

The authors thank to the Coordenação de Aperfeiçoamento de Pessoal de Nível Superior (CAPES) and Conselho Nacional de 
Desenvolvimento Científico e Tecnológico for providing financial support.

\section{References}

Ahmed, J., Kaur, A., Shivhare, U., 2002. Color degradation kinetics of Spinach, mustard leaves, and mixed puree. J. Food Sci. 67 2692-2695.

Achir, N., Randrianatoandro, V.A., Bohuon, P., Laffargue, A., Avallone, S., 2010. Kinetic study of $\beta$-carotene and lutein degradation in oils during heat treatment. Eur. J. Lipid Sci. Technol. 112, 349-361.

Anarjan, N., Tan, C.P., 2013. Effects of storage temperature, atmosphere and light on chemical stability of astaxanthinnanodispersions. J. Am. Oil Chem. Soc. 90, 1223-1227.

Aparicio-Ruiz, R., Mínguez-Mosquera, M.I., Gandul-Rojas, B., 2011. Thermal degradation kinetics of lutein, $\beta$-carotene and $\beta$-cryptoxanthinin virgin olive oils. J. Food Compos. Anal. 24, 811-820.

Bozalan, N.K., Karadeniz, F., 2011. Carotenoid profile, total phenolic content, and antioxidant activity of carrots. Int. J Food Prop. 14, 1060-1068.

Bhupathiraju, S.N., Wedick, N.M., Pan, A., Manson, J.E., Rexrode, K.M., Willett, W.C., Rimm, E.B., Hu, F.B., 2013. Quantity and variety in fruit and vegetable intake and risk of coronary heart disease. Am. J. Clin. Nutr. 98, 1514-1523.

Calvo, M.M., Santa-María, G., 2008. Effect of illumination and chlorophylls on stability of tomato carotenoids. Food Chem. 107, 1365-1370.

Campardelli, R., Adami, R., Reverchon, E., 2012. Preparation of stable aqueous nanodispersions of $\beta$-carotene by supercritical assisted injection in a liquid antisolvent. Procedia Eng. 42, 1493-1501.

Chen, B.H., Chen, T.M., Chien, J.T., 1994. Kinetic model for studying the isomerization of.alpha.-and.beta.-carotene during heating and illumination. J. Agric. Food. Chem. 42, 2391-2397.

Chen, B.H., Huang, J.H., 1998. Degradation and isomerization of chlorophyll a and $\beta$-carotene as affected by various heating and illumination treatments. Food Chem. 62, 299-307.

Chen, L., Bai, G., Yang, R., Zang, J., Zhou, T., Zhao, G., 2014. Encapsulation of $\beta$-carotene within ferritin nanocages greatly increases its water-solubility and thermal stability. Food Chem. 149, 307-312.

Chen, H., Zhong, Q., 2015. Thermal and UV stability of $\beta$-carotene dissolved in peppermint oil microemulsified by sunflower lecithin and Tween 20 blend. Food Chem. 174, 630-636.

De Paz, E., Martín, A., Mateos, E., Cocero, M.J., 2013. Production of water-soluble $\beta$-carotene micellar formulations by novel emulsion techniques. Chem. Eng. Process. 74, 90-96.

Desu, H.R., Narang, A.S., Thoma, L.A., Mahato, R.I., 2013. Liquid dosage forms. In: Dash, A.K., Singh, S., Tolman, J. (Eds.), Pharmaceutics: Basic Principles and Application to Pharmacy Practice. Academic Press, pp. 181-224.

EU Commission, 2011. Commission Recommendation of 18 October 2011 On The Definition of Nanomaterial (2011/696/EU). Official Journal of the European Communities: Legis.

Frozza, R.L., Bernardi, A., Paese, K., Hoppe, J.B., Silva, T., Battastini, A.M., Pohlmann, A.R., Guterres, S.S., Salbego, C., 2010. Characterization of trans-resveratrol-loaded lipid-core nanocapsules and tissue distribution studies in rats. J. Biomed. Nanotechnol. 6, 694-703.

Gammone, M.A., Riccioni, G., D'orazio, N., 2015. Carotenoids: potential allies of cardiovascular health? Food Nutr. Res., 59

Giménez, P.J., Fernández-López, J.A., Angosto, J.M., Obón, J.M., 2015. Comparative thermal degradation patterns of natural yellow colorants used in foods. Plant Foods Hum. Nutr. 70, 380-387

González-Reza, R.M., Quintanar-Guerrero, D., Flores-Minutti, J.J., Gutiérrez-Cortez, E., Zambrano-Zaragoza, M.L., 2015. Nanocapsules of $\beta$-carotene: thermal degradation kinetics in a scraped surface heat exchanger (SSHE). LWT-Food Sci. Technol. 60, 124-130.

Hadjal, T., Dhuique-Mayer, C., Madani, K., Dornier, M., Achir, N., 2013. Thermal degradation kinetics of xanthophylls from blood orange in model and real food systems. Food Chem. 138, 2442-2450.

Henry, L.K., Catignani, G.L., Schwartz, S.J., 1998. Oxidative degradation kinetics of lycopene, lutein,and 9-cis and all-trans $\beta$-carotene. J. Am. Oil Chem. Soc. 75, 823-829.

Huang, Q., Yu, H., Ru, Q., 2010. Bioavailability and delivery of nutraceuticals using nanotechnology. J. Food Sci. 75, R50-R57.

Hwang, E.S., Stacewicz-Sapuntzakis, M., Bowen, P.E., 2012. Effects of heat treatment on the carotenoid and tocopherol composition of tomato. J. Food Sci. 77, C1109-C1114.

Jiménez, M.M., Pelletier, J., Bobin, M.F., Martini, M.C., 2004. Influence of encapsulation on the in vitro percutaneous absorption of octylmethoxycinnamate. Int. J. Pharm. 272, $45-55$.

Khachik, F., Moura, F.F., Zhao, D.Y., Aebischer, C.P., Bernstein, P.S. 2002. Transformations of selected carotenoids in plasma, liver, and ocular tissues of humans and in nonprimate animal models. Invest. Ophthalmol. Visual Sci. 43, 3383-3392.

Khoo, H.E., Prasad, K.N., Kong, K.W., Ismail, A., 2011. Carotenoids and their isomers: color pigments in fruits and vegetables. Molecules 16, 1710-1738.

Knockaert, G., Pulissery, S.K., Lemmens, L., Buggenhout, S.V., Hendrickx, M., Loey, A.V., 2012. Carrot $\beta$-carotene degradation and isomerization kinetics during thermal processing in the presence of oil. J. Agric. Food. Chem. 60, 10312-10319.

Kopec, R.E., Cooperstone, J.L., Schweiggert, R.M., Young, G.S. Harrison, E.H., Francis, D.M., Clinton, S.K., Schwartz, S.J., 2014. Avocado consumption enhances human postprandial provitamin A absorption and conversion from a novel high- $\beta$-carotene tomato sauce and from carrots. J. Nutr. 144, 1158-1166.

Lai, O.M., Tan, C.P., Akoh, C.C., 2012. Palm Oil: Production, Processing, Characterization, and Uses. AOCS Press.

Lerfall, J., 2016. Carotenoids: occurrence, properties and determination. In: Caballero, B., Finglas, P., Toldrá, F. (Eds.), Encyclopedia of Food and Health. Elsevier, Trondheim, Norway, pp. 663-669.

Li, D., Xiao, Y., Zhang, Z., Liu, C., 2015. Light-induced oxidation and isomerization of all-trans- $\beta$-cryptoxanthin in a model system. J. Photochem. Photobiol. B 142, 51-58.

Lobato, K.B.S., Paese, K., Forgearini, J.C., Guterres, S.S., Jablonski, A., Rios, A.O., 2013. Characterisation and stability evaluation of bixinnanocapsules. Food Chem. 141, 3906-3912.

Lobato, K.B.S., Paese, K., Forgearini, J.C., Guterres, S.S., Jablonski, A., Rios, A.O., 2015. Evaluation of stability of bixin in nanocapsules in model systems of photosensitization and heating. LWT-Food Sci. Technol. 60, 8-14.

Lu, M.S., Fang, Y.J., Chen, Y.M., Luo, W.P., Pan, Z.Z., Zhong, X., Zhang, C.X., 2015. Higher intake of carotenoid is associated with a lower risk of colorectal cancer in Chinese adults: a case-control study. Eur. J. Nutr. 54, 619-628.

Lim, A.S.L., Griffin, C., Roos, Y.H., 2014. Stability and loss kinetics of lutein and $\beta$-carotene encapsulated in freeze-dried emulsions with layered interface and trehalose as glass former. Food Res. Int. 62, 403-409.

Mazzarino, L., Travelet, C., Ortega-Murillo, S., Otsuka, I., Pignot-Paintrand, I., Lemos-Senna, E., Borsali, R., 2012. Elaboration of chitosan-coated nanoparticles loaded with curcumin for mucoadhesive applications. J. Colloid Interface Sci. 370, 58-66

Maurer, M.M., Mein, J.R., Chaudhuri, S.K., Constant, H.L., 2014. An improved UHPLC-UV method for separation and quantification of carotenoids in vegetable crops. Food Chem $165,475-482$

Minguez-Mosquera, M.I., Jaren-Galan, M., 1995. Kinetics of the decolouring of carotenoid pigments. J. Sci. Food Agric. 67, 153-161.

Mora-Huertas, C.E., Fessi, H., Elaissari, A., 2010. Polymer-based nanocapsules for drug delivery. Int. J. Pharm. 385, 113-142. 
Mora-Huertas, C.E., Couenne, F., Fessi, H., Elaissari, A., 2012. Electrokinetic properties of poly-e-caprolactone-based nanoparticles prepared by nanoprecipitation and emulsification-diffusion methods: a comparative study. J. Nanopart. Res. 14.

Namitha, K.K., Negi, P.S., 2010. Chemistry and biotechnology of carotenoids. Crit. Rev. Food Sci. Nutr. 50, 728-7760.

Oliveira, C.P., Venturini, C.G., Donida, B., Poletto, F.S., Guterres, I.S., Pohlmann, A.R., 2013. An algorithm to determine the mechanism of drug distribution in lipid-core nanocapsule formulations. Soft Matter 9, 1141-1150.

Ourique, A.F., Pohlmann, A.R., Guterres, S.S., Beck, R.C.R., 2008. Tretinoin-loaded nanocapsules: preparation, physicochemical characterization, and photostability study. Int. J. Pharm. 352, $1-4$.

Polyakov, N.E., Leshina, T.V., Konovalona, T.A., Kispert, L.D., 2001. Carotenoids as scavengers of free radicals in a fenton reaction: antioxidants or pro-oxidants? Free Radic. Biol. Med. 31, 398-404.

Pogson, B., Mcdonald, K.A., Truong, M., Britton, G., Dellapenna, D., 1996. Arabidopsis carotenoid mutants demonstrate that lutein is not essential for photosynthesis in higher plants. Plant Cell 8, 1627-1639.

Rakcejeva, T., Augspole, I., Dukalska, L., Dimins, F., 2012. Chemical composition of variety 'Nante' hybrid carrots cultivated in Latvia. Int. J. Biol. Biomol. Agric. Food Biotechnol. Eng. 6, 188-194.

Ribeiro, B.D., Oliveira, R.G., 2013. Carotenoids as colorants. In: Natural Products. Springer Berlin Heidelberg, pp. 4017-4036.

Rigo, L.A., Frescura, V., Fiel, L., Coradini, K., Ourique, A.F., Emanuelli, T., Quatrin, A., Tedesco, S., Silva, C.B., Guterres, S.S., Pohlmann, A.R., Beck, R.C.R., 2014. Influence of the type of vegetable oil on the drug release profile from lipid-core nanocapsules and in vivo genotoxicity study. Pharm. Dev. Technol. 19, 789-798.

Sáiz-Abajo, M.J., González-Ferrero, C., Moreno-Ruiz, A., Romo-Hualde, A., González-Navarro, C.J., 2013. Thermal protection of $\beta$-carotene in re-assembled casein micelles during different processing technologies applied in food industry. Food Chem. 138, 1581-1587.

Santos, P.P., Paese, K., Guterres, S.S., Pohlmann, A.R., Costa, T.H., Jablonski, A., Flôres, S.H., Rios, A.O., 2015. Development of lycopene-loaded lipid-core nanocapsules: physicochemical characterization and stability study. J. Nanopart. Res. 17, 1-11.

Saxena, A., Maity, T., Raju, P.S., Bawa, A.S., 2012. Degradation kinetics of colour and total carotenoids in jackfruit (Artocarpusheterophyllus) bulb slices during hot air drying. Food Bioprocess Technol. 5, 672-679.

Schieber, A., Carle, R., 2005. Occurrence of carotenoid cis-isomers in food: technological, analytical, and nutritional implications. Trends Food Sci. Technol. 16, 416-422.
Silva, M.M., Nora, L., Cantillano, R.F.F., Paese, K., Guterres, S.S., Pohlmann, A.R., Costa, T.M.H., Rios, A.O., 2016. The production, characterization, and the stability of carotenoids loaded in lipid-core nanocapsules. Food Bioprocess Technol. 9, 1148-1158.

Siqueira, N.M., Contri, R.V., Paese, K., Beck, R.C.R., Pohlmann, A.R., Guterres, S.S., 2011. Innovative sunscreen formulation based on benzophenone-3-loaded chitosan-coated polymeric nanocapsules. Skin Pharmacol. Physiol. 24, 166-174.

Spada, J.C., Noreña, C.P.Z., Marczak, L.D.F., Tessaro, I.C., 2012. Study on the stability of $\beta$-carotene microencapsulated with pinhão (Araucaria angustifolia seeds) starch. Carbohydr. Polym. 89, 1166-1173.

Tang, Y.C., Chen, B.H., 2000. Pigment change of freeze-dried carotenoid powder during storage. Food Chem. 69, 11-17.

Venturini, C.G., Jäger, E., Oliveira, C.P., Bernardi, A., Battastini, A.M.O., Guterres, S.S., Pohlmann, A.R., 2011. Formulation of lipid core nanocapsules. Colloid Surf. A 375, 200-208.

Wang, Y., Gapstur, S.M., Gaudet, M.M., Furtado, J.D., Campos, H., Mccullough, M.L., 2015. Plasma carotenoids and breast cancer risk in the cancer prevention study II nutrition cohort. Cancer Causes Control 26, 1233-1244.

Wang, Y., Hong, Y., Zhou, C., Lv, F., Bie, X., Lu, Z., 2012. Study on the spray-drying encapsulation of lutein in the porous starch and gelatin mixture. Eur. Food Res. Technol. 234, 157-163.

Wu, J., Cho, E., Willet, W.C., Sastry, S.M., Schaumberg, D.A., 2015. Intakes of lutein, zeaxanthin, and other carotenoids and age-related macular degeneration during 2 decades of prospective follow-up. JAMA Ophthalmol. 133, 1415-1424.

Yahia, E.M., Ornelas-Paz, J.J., 2010. Chemistry, stability, and biological actions of carotenoids. In: De La Rosa, L.A., Alvarez-Parrilla, E., Gonzalez-Aguilar, G.A. (Eds.), Fruit and Vegetable Phytochemicals: Chemistry, Nutritional Value and Stability. Wiley-Blackwell, Ames, pp. 177-222.

Zanotto-Filho, A., Coradini, K., Braganhol, E., Schröder, R., Oliveira, C.M., Simões-Pires, A., Battastini, A.M.O., Pohlmann, A.R., Guterres, S.S., Forcelini, C.M., Beck, R.C.R., Moreira, J.C.F., 2013. Curcumin-loaded lipid-core nanocapsules as a strategy to improve pharmacological efficacy of curcumin in glioma treatment. Eur. J. Pharm. Biopharm. 83, 156-167.

Zepka, L.Q., Borsarelli, C.D., Silva, M.A.A.P., Mercadante, A.Z., 2009. Thermal degradation kinetics of carotenoids in a cashew apple juice model and its impact on the system color. J. Agric. Food Chem. 57, 7841-7845.

Zu, K., Mucci, L., Rosner, B.A., Clinton, S.K., Loda, M., Stampfer, M.J., Giovannucci, E., 2014. Dietary lycopene, angiogenesis, and prostate cancer: a prospective study in the prostate-specific antigen era. J. Natl. Cancer Inst. 106. 